http://dx.doi.org/10.32929/2446-8355.2019v28n4p478-492

\title{
ATRIBUTOS FÍSICOS DE LATOSSOLO VERMELHO DISTROFÉRRICO CULTIVADO COM CANA-DE-AÇÚCAR EM FUNÇÃO DO PREPARO E LOCAL DE AMOSTRAGEM
}

Sálvio Napoleão Soares Arcoverde ${ }^{1 *}$, Cristiano Márcio Alves de Souza ${ }^{2}$, Weslley Rodrigues Santos $^{3}$, Hideo de Jesus Nagahama ${ }^{4}$, Andrés Hideki Tanaka Suaréz ${ }^{3}$, Paulo Alexandre Graciano Maciak $^{3}$

\footnotetext{
${ }^{1}$ PNPD, Pós-graduação em Engenharia Agrícola, Universidade Federal da Grande Dourados, Dourados, MS. Rodovia Dourados-Itahum, km 12, Cidade Universitária, CEP: 79804-970, Dourados, MS. *Autor correspondente: salvionapoleao@gmail.com:

${ }^{2}$ Docente, Engenharia Agrícola, Universidade Federal da Grande Dourados, Dourados, MS.

${ }^{3}$ Engenheiro Agrícola, Universidade Federal da Grande Dourados, Dourados, MS.

${ }^{4}$ Engenheiro Agrônomo, Engenharia Agrícola e Ambiental, Universidade Federal do Vale do São Francisco, Juazeiro, BA.
}

Recebido: 15/12/2018; Aceito: 18/12/2019

RESUMO: O estabelecimento de manejos conservacionistas do solo traz benefícios em sistemas de produção de culturas anuais, mas para a cana-de-açúcar são incipientes as informações sobre tais efeitos na qualidade de solos. Objetivou-se avaliar os sistemas de preparo reduzido e plantio direto, bem como o local de amostragem nos atributos físicos de um Latossolo Vermelho Distroférrico cultivado com cana-planta. O trabalho foi realizado na Universidade Federal da Grande Dourados (UFGD), onde a área experimental foi dividida em duas subáreas, compostas pelo plantio direto e preparo reduzido. Em cada preparo foram plantadas oito cultivares de cana-de-açúcar em delineamento inteiramente casualizado, com quatro repetições. Nas unidades experimentais, coletaram-se amostras de solo com estrutura preservada na linha e na entrelinha do rodado do trator para avaliação da densidade do solo; macroporosidade; microporosidade; porosidade total; umidade gravimétrica do solo e resistência à penetração no anel com penetrômetro de bancada (RP anel), nas camadas de 0,00-0,10 e 0,10-0,20 m. Além das referidas posições de amostragem, considerou-se também a da linha de cana para avaliar a resistência mecânica do solo à penetração (RP) com penetrômetro de campo, determinando-se a RP média e máxima, nas camadas de 0,00-0,10; $0,10-0,20 ; 0,20-0,30 ; 0,30-0,40 \mathrm{~m}$. O preparo reduzido aumentou a macroporosidade na camada superficial. Não houve efeito do preparo para porosidade total e microporosidade. $\mathrm{Na}$ camada (0,00-0,40 m) ocorreu redução da RP média e máxima, do rodado, seguida do entrerrodado e linha de plantio, respectivamente; além de maiores valores destes atributos na camada $(0,20-0,40 \mathrm{~m})$ da linha de plantio.

Palavras-chave: Entrerrodado. Plantio direto. Preparo reduzido. Rodado.

\author{
DYSTROFERRIC RED LATOSOL PHYSICAL (OXISOL) ATTRIBUTES \\ CULTIVATED WITH SUGAR CANE AS AFFECTED BY SOIL TILLAGE AND \\ SAMPLING LOCATION
}


ABSTRACT: The establishment of soil conservation management has benefits in annual crop production systems, for sugarcane, information on such effects on soil quality is incipient. The objective of this study was to evaluate the reduced tillage and no-tillage systems, as tracks as the sampling site on the physical attributes of a Dystroferric Red Latosol (Oxisol) under cane cultivation. The work was conducted at Federal University of Grande Dourados (UFGD), where the experimental area was divided into two subareas, composed by no-tillage and reduced tillage. Eight sugarcane cultivars were cultivated in each preparation in a completely randomized design, with four replications. In the experimental units, soil samples were collected with a preserved structure in the row and in the row of the tracks to evaluate the attributes: soil density; macroporosity; microporosity; total porosity; soil moisture and resistance to penetration in the bench with penetrometer bench, in the layers of $0.00-0.10$ and $0.10-0.20 \mathrm{~m}$. In addition to the mentioned sampling positions, it was also considered that of the cane row to evaluate the mechanical resistance of the soil to the penetration (PR) with field penetrometer, determining the mean and maximum $\mathrm{PR}$ in the layers of $0.00-0.10 ; 0.10-0.20 ; 0.20-0.30 ; 0.30-0.40 \mathrm{~m}$. PR increased macroporosity in the superficial layer. There was no preparation effect for total porosity and microporosity. In the layer $(0.00-0.40 \mathrm{~m})$ there was reduction of the mean and maximum PR, of the tracks, followed by the between tracks and planting row, respectively; besides higher values of these attributes in the layer $(0.20-0.40 \mathrm{~m})$ of the planting row.

Key words: Between tracks. Soil compaction. No-tillage. Reduced tillage. Tracks.

\section{INTRODUÇÃO}

A crescente demanda por produtos derivados da cana-de-açúcar é responsável pelo crescimento do setor sucroenergético brasileiro, por meio da expansão dos canaviais e investimentos na construção de novas usinas no Brasil e principalmente no Mato Grosso do Sul. Tal demanda do setor requer intensa mecanização agrícola altamente tecnificada em todo o ciclo da cultura, com máquinas modernas e versáteis que executem trabalhos com máxima eficiência e baixo custo, a fim de destinar matéria-prima de qualidade à agroindústria (SOUZA et al., 2012).

No cultivo da cana-de-açúcar se faz necessário à prática de sucessivas operações de preparo do solo, com a utilização de arados, grades e subsoladores, além da atuação de máquinas e implementos que contribuem na degradação estrutural do solo e no aumento da compactação (SILVA JUNIOR et al., 2013; SOUZA et al., 2014). Com isso, normalmente há redução da qualidade do solo em sistemas com intensa mobilização, devido às alterações ocasionadas nos atributos físicos do solo, como aumento da densidade e consequentemente da resistência mecânica do solo à penetração (SILVA JUNIOR et al., 2013; MARASCA et al., 2015; SILVA; CASTRO, 2015).

O contínuo tráfego de máquinas/implementos também acarreta compactação superficial do solo (ARCOVERDE et al., 2019c), sobretudo na entrelinha da cana-de-açúcar, onde há significativo desenvolvimento do sistema radicular da planta (CURY et al., 2014; OHASHI et $a l .$, 2015). Frente aos impactos de tais práticas de manejo do solo, tem se questionado o uso 
de operações sucessivas de preparo para implantação de canaviais, visto que estes, muitas vezes, ocupam áreas sem restrição de fertilidade e impedimento físico, com maior demanda energética e aumento do custo operacional (CARVALHO et al., 2011).

A adoção de sistemas conservacionistas, por outro lado, com mínima mobilização do solo, manutenção de resíduos em superfície, conservação da estrutura e redução do gasto energético, ainda que de maneira lenta vem ocorrendo no sistema de produção da cana-deaçúcar. Há relatos de que, operacionalmente, o plantio direto de cana, em área de reforma, consiste de duas etapas sucessivas (implantação e estabelecimento), em que na primeira são vencidas as restrições físicas e de fertilidade; enquanto na segunda não mais se prepara o solo, mantendo-o coberto com o palhiço remanescente e com revolvimento apenas no sulco de plantio.

No entanto, poucas pesquisas relacionam tais efeitos de sistemas conservacionistas sobre a qualidade física de solos cultivados com cana-de-açúcar, principalmente àqueles com elevado potencial de compactação como os Latossolos argilosos (SILVA; CASTRO, 2015). Além disso, as informações existentes em pesquisas relacionam-se aos efeitos do tráfego de conjuntos mecanizados em operações de colheita mecanizada, mas não evidenciam os efeitos ocasionais destas em solos suscetíveis à compactação sob diferentes sistemas de manejo no início do ciclo da cultura da cana-de-açúcar.

Por esta razão, objetivou-se avaliar os sistemas de preparo reduzido e plantio direto, bem como o local de amostragem nos atributos físicos de um Latossolo Vermelho Distroférrico cultivado com cana-planta.

\section{MATERIAL E MÉTODOS}

O experimento foi instalado na Fazenda Experimental da Universidade Federal da

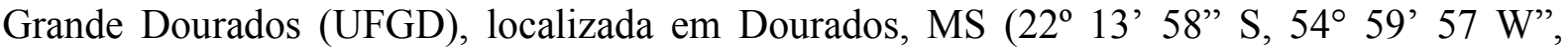
altitude $418 \mathrm{~m}$ ), em julho de 2016. O clima da região, segundo classificação de Köppen (ALVARES et al., 2013), é tropical (Aw) com estação quente e chuvosa no verão e seca no inverno, com temperatura média anual do ar de $23{ }^{\circ} \mathrm{C}$ e precipitação pluvial média anual de $1.635 \mathrm{~mm}$. O solo é classificado como LATOSSOLO VERMELHO Distroférrico (SANTOS et al., 2018), textura argilosa, tendo na camada até $0,30 \mathrm{~m}$ de profundidade $603 \mathrm{~g} \mathrm{~kg}^{-1}$ de argila, $147 \mathrm{~g} \mathrm{~kg}^{-1}$ de silte e $250 \mathrm{~g} \mathrm{~kg}^{-1}$ de areia.

A área destinada ao experimento, que estava há 14 anos sob cultivo de soja e milho, em um sistema de sucessão de culturas sem revolvimento do solo, apresentava homogeneidade das condições ambientais, localizada em topografia plana, sem variação do tipo de solo e técnicas de manejo. A mesma foi dividida em duas subáreas, compostas pelos sistemas plantio direto e preparo reduzido. Um dia após o preparo do solo, promoveu-se a sulcação da área experimental, à profundidade de $20-30 \mathrm{~cm}$. No dia seguinte, realizou-se a aplicação manual de 0,3 $\mathrm{Mg} \mathrm{ha}^{-1}$ da formulação 10-25-26 de NPK no sulco de plantio, de modo uniforme para toda a área experimental (ARCOVERDE et al., 2018; ARCOVERDE et al., 2019a; ARCOVERDE et al., 2019b; ARCOVERDE et al., 2019d). No dia 21 de julho de 2016, realizou-se o plantio, de forma convencional, adotando-se o plantio de inverno, sendo 
oito cultivares de cana (RB965902, RB985476, RB966928, RB855156, RB975201, RB975242, RB036066 e RB855536) plantadas manualmente (ARCOVERDE et al., 2018; ARCOVERDE et al., 2019a; ARCOVERDE et al., 2019b; ARCOVERDE et al., 2019d). As mudas foram retiradas em viveiro adjacente à área experimental, as quais, em seguida, foram distribuídas, utilizando-se a densidade média de 15 gemas por metro de sulco, por meio da distribuição de colmos "pé-com-ponta", e, posteriormente, efetuou-se o corte manual dos colmos, em toletes de 3 gemas, os quais foram cobertos com uma camada de solo (SANTOS et al., 2010).

Cada unidade experimental continha 5 linhas de cana com 5 metros de comprimento, espaçadas de $1,50 \mathrm{~m}\left(37,5 \mathrm{~m}^{2}\right)$. O delineamento experimental foi inteiramente casualizado, em esquema fatorial $2 \times 2$, sendo dois sistemas de preparo do solo (plantio direto e preparo reduzido) e duas posições de amostragem (na linha do rodado e entrerrodado do trator), e 32 repetições. Ressalta-se que, devido à recente implantação da cultura de cana-de-açúcar, as cultivares de cana não foram consideradas como fator de variação.

O sistema de preparo reduzido consistiu de gradagem pesada. Foi utilizada grade aradora do tipo off-set, arrastada, com 16 discos de 0,76 m de diâmetro (30") em cada seção, na profundidade de $0,15 \mathrm{~m}$. O sistema plantio direto consistiu de controle mecanizado (trituração) das plantas daninhas, e posteriormente, abertura de sulcos para plantio. Foi utilizado triturador de palhas equipado com rotor de facas curvas de aço que trabalham em alta rotação e sulcador para abertura dos sulcos para plantio.

Para as operações de preparo e abertura de sulcos para plantio, foi utilizado o trator $4 \times 2$ New Holland, modelo 8030 de potência no motor de 89,79 kW (122 cv), rotação de 2200 rpm, $3^{\text {a }}$ marcha reduzida, pneus dianteiros $14.9-58$ e traseiros $23.1-30$, e massa de $4,51 \mathrm{Mg}$. Para a cobertura dos sulcos e tratos culturais, em ambos os sistemas de preparo, foi utilizado o trator 4x2 TDA Massey Fergusson, modelo MF292 de potência no motor 68,74 kW (92 cv), rotação de $2200 \mathrm{rpm}, 3^{\mathrm{a}}$ marcha reduzida, pneus dianteiros 7.50-18 e traseiros 18.4-34, e massa de 3,40 Mg; e pulverizador KO Cross-s 2000, pneus 9.5-24, $14 \mathrm{~m}$ de barra e massa de $1,40 \mathrm{Mg}$.

Para a avaliação dos atributos físicos do solo, em cada sistema de preparo foram coletadas amostras com estrutura preservada, após o tráfego inicial de máquinas para tratos culturais. Nas duas entrelinhas centrais de cada unidade experimental, duas trincheiras foram abertas aleatoriamente, com coletas de amostras nas camadas de 0,00-0,10 e 0,10-0,20 m, em dois diferentes pontos: rodado e entrerrodado do trator.

As amostras de solo foram envolvidas em papel filme e acondicionadas em geladeira, visando o mínimo de alteração estrutural e manutenção do conteúdo de água da amostra. Após a preparação das amostras em laboratório, determinou-se a umidade gravimétrica do solo (TEIXEIRA et al., 2017).

A porosidade total do solo $(\mathrm{Pt})$ foi obtida pela diferença entre a massa do solo saturado e a massa do solo seco em estufa a $110{ }^{\circ} \mathrm{C}$ durante $24 \mathrm{~h}$; a microporosidade do solo (Mi) determinada pelo método da mesa de tensão com uma coluna de água de 0,60 $\mathrm{m}$ de altura (TEIXEIRA et al., 2017). A macroporosidade (Ma) é a diferença entre a Pt e 
Mi (TEIXEIRA et al., 2017). A densidade do solo (Ds) foi calculada pela relação entre a massa seca a $110^{\circ} \mathrm{C}$ durante $24 \mathrm{~h}$ da amostra de solo do anel volumétrico e o volume do mesmo anel (TEIXEIRA et al., 2017). Ao atingir o equilíbrio na tensão correspondente a coluna de água de $0,60 \mathrm{~m}$ de altura, a resistência do solo à penetração ( $R P$ anel) foi determinada, por meio de penetrógrafo eletrônico com velocidade constante de penetração de $10 \mathrm{~mm} \mathrm{~min}{ }^{-1}$, diâmetro de base da haste de $4 \mathrm{~mm}$ e semiângulo de $30^{\circ}$. As amostras obtidas nos $5 \mathrm{~mm}$ superiores e inferiores da amostra foram descartadas, visando eliminar o efeito da periferia da amostra. A frequência de leituras de RP anel correspondeu à coleta de um valor a cada 0,25 s, obtendo-se 800 leituras por amostra, sendo utilizado o valor médio (BERGAMIN et al., 2010; ARCOVERDE et al., 2019a; ARCOVERDE et al., 2019b).

Foi realizado o teste de resistência mecânica do solo à penetração (RP), utilizando o penetrômetro de campo modelo PenetroLOG - PLG 1020, com aptidão eletrônica para aquisição de dados. Foram coletados 5 pontos aleatórios no centro das entrelinhas da unidade experimental, em seguida determinando-se a RP média e máxima estratificadas nas camadas de 0,00-0,10; 0,10-0,20; 0,20-0,30; 0,30-0,40 m (ARCOVERDE et al., 2019a; ARCOVERDE et al., 2019b). Foram feitos três pontos de amostragens: linha da cana, entrerrodado e rodado do trator.

Os dados de RP anel, Ds, Pt, Ma, Mi e umidade gravimétrica do solo (U) foram analisados em esquema fatorial 2 (preparo do solo) x 2 (posição de amostragem). Para a RP, foi considerada também a posição de amostragem (linha da cana) e analisada como um fatorial 2 (preparo do solo) x 3 (posição de amostragem). Para todos os atributos analisados, o número de repetições correspondeu ao de unidades experimentais por tratamento, ou seja, 32 repetições.

As médias foram submetidas à análise de variância e, quando significativa, comparadas pelo teste de Student-Newman-Keuls (SNK) a 5\% de probabilidade.

\section{RESULTADOS E DISCUSSÃO}

A análise dos atributos físicos do solo indicou que houve interação entre os fatores estudados apenas para densidade do solo (Ds) e que, de forma geral, não houve diferença entre os tratamentos para porosidade total (Pt) e microporosidade (Mi) (Tabela 1), inclusive não foi observada significância do fator posição para macroporosidade (Ma), na camada de 0,00-0,10 m. Resultado semelhante ocorreu para Ds, na camada de 0,10-0,20 m, mas não houve interação entre os fatores para Ma, Mi e Pt. Esses resultados podem estar associados aos efeitos dos manejos anteriores, haja vista recente implantação do sistema de cultivo da cana-de-açúcar.

Houve efeito do preparo e posição para umidade gravimétrica do solo (U), nas camadas de 0,00-0,10 e 0,10-0,20 m (Tabela 1), observando-se valores mais elevados no preparo reduzido e na posição do entrerrodado em ambas as camadas (Tabela 2). Esses resultados podem ser atribuídos à recente implantação dos sistemas de preparo do solo para o cultivo de cana. Ramos et al. (2013) reportaram que o conteúdo de água no solo depende dos atributos físicos do solo relacionados a sua estrutura, seguida da textura e da matéria orgânica. Nesse 
sentido, espera-se que, ao longo do tempo, no sistema plantio direto, devido a não mobilização e ao incremento de resíduos vegetais sobre o solo, ocorra maior valor de U no solo em comparação ao preparo reduzido.

Tabela 1. Resumo da análise de variância da densidade do solo (Ds), umidade do solo (U), porosidade total $(\mathrm{Pt})$, macroporosidade $(\mathrm{Ma})$, microporosidade $(\mathrm{Mi})$ e resistência à penetração no anel (RP anel) por camada de solo, nos tratamentos preparo do solo (P) e posição de amostragem (PS). Dourados, MS, UFGD, 2016. Abstract of the variance analisys of soil density (Ds), soil moisture (U), total porosity (Pt), macroporosity (Ma), microporosity (Mi), soil density $(D s)$ and soil penetration resistance in the ring $(P R)$ per soil layer, in soil tillage (P) and sampling location (SP) treatments. Dourados, MS, UFGD, 2016.

\begin{tabular}{|c|c|c|c|c|c|c|}
\hline \multirow{3}{*}{ Fonte de variação } & \multicolumn{6}{|c|}{ Camada $(\mathrm{m})$} \\
\hline & \multicolumn{6}{|c|}{$0,00-0,10$} \\
\hline & Ds & $\mathrm{U}$ & $\mathrm{Ma}$ & $\mathrm{Mi}$ & $\mathrm{Pt}$ & RP anel \\
\hline $\mathrm{P}$ & $7,46^{* *}$ & $5,96^{*}$ & $7,19^{\text {** }}$ & $0,05^{\mathrm{ns}}$ & $2,28^{\mathrm{ns}}$ & $3,74^{\mathrm{ns}}$ \\
\hline OS & $5,51^{*}$ & $3,97^{*}$ & $1,22^{\mathrm{ns}}$ & $1,29^{\mathrm{ns}}$ & $3,10^{\mathrm{ns}}$ & $9,38^{* *}$ \\
\hline \multirow[t]{3}{*}{$\mathrm{P} \times \mathrm{OS}$} & $0,00^{* *}$ & $0,32^{\mathrm{ns}}$ & $0,05^{\mathrm{ns}}$ & $0,67^{\mathrm{ns}}$ & $0,38^{\mathrm{ns}}$ & $0,00^{\mathrm{ns}}$ \\
\hline & \multicolumn{6}{|c|}{$0,10-0,20$} \\
\hline & Ds & $\mathrm{U}$ & $\mathrm{Ma}$ & $\mathrm{Mi}$ & $\mathrm{Pt}$ & RP anel \\
\hline $\mathrm{P}$ & $7,24^{* *}$ & $10,67^{* *}$ & $3,85^{\mathrm{ns}}$ & $1,72^{\mathrm{ns}}$ & $1,11^{\mathrm{ns}}$ & $1,62^{\mathrm{ns}}$ \\
\hline OS & $0,59^{\mathrm{ns}}$ & $8,05^{* *}$ & $2,68^{\mathrm{ns}}$ & $1,39^{\mathrm{ns}}$ & $0,66^{\mathrm{ns}}$ & $0,51^{\mathrm{ns}}$ \\
\hline $\mathrm{P} \times \mathrm{OS}$ & $5,75^{*}$ & $1,53^{\mathrm{ns}}$ & $3,03^{\mathrm{ns}}$ & $0,42^{\mathrm{ns}}$ & $1,72^{\mathrm{ns}}$ & $1,37^{\mathrm{ns}}$ \\
\hline
\end{tabular}

ns não significativa, a $5 \%$ de probabilidade ** Significativo a $1 \%$ de probabilidade, $*$ Significativo a $5 \%$ de probabilidade. ns: not significant a 5\% at 5\% probability, ** Significant at 1\% probability, * Significant at 5\% probability.

Fonte: Autoria própria. Own authorship.

A Ma também foi outro atributo físico do solo que para o fator preparo na camada 0,00 $0,10 \mathrm{~m}$, obteve valores superiores no preparo reduzido $\left(0,05 \mathrm{~m}^{3} \mathrm{~m}^{-3}\right)$, enquanto que o plantio direto apresentou valor de $0,04 \mathrm{~m}^{3} \mathrm{~m}^{-3}$. O que pode ser explicado pela não mobilização do solo associado ao tráfego de máquinas para controle de plantas daninhas. Estes valores são considerados baixos (Tabela 2), já que o valor de $0,10 \mathrm{~m}^{3} \mathrm{~m}^{-3}$ tem sido apontado como o mínimo adequado para as trocas líquidas e gasosas entre o ambiente externo e o solo, e por ser parâmetro considerado crítico para o crescimento das raízes da maioria das culturas (ROSSETTI; CENTURION, 2013).

A Pt e a Mi não diferiram entre os tratamentos estudados para as camadas de $0,00-0,10$ e 0,10-0,20 m (Tabela 2); entretanto, Silva Junior et al. (2013) afirmaram que, com o revolvimento do solo no preparo reduzido ocorre aumento da $\mathrm{Pt}$, em relação ao sem mobilização. Quanto à Mi, conforme relatam Bergamin et al. (2010) e Arcoverde et al. (2019c), em Latossolo Vermelho distroférrico, a composição mineralógica da fração argila condiciona o comportamento deste atributo em relação ao manejo do solo, contrariamente ao que ocorre com a Ma.

A não significância de Pt (Tabela 2), para as camadas 0,00-0,10 e 0,10-0,20 m, possivelmente deva-se em razão do tráfego de máquinas na entrelinha da cana desde o início do ciclo da cultura, o que promoveu estado de compactação no preparo reduzido semelhante 
ao plantio direto. Outro aspecto a ser considerado foram os altos valores de $\mathrm{Mi}$, resultado do alto teor de argila do Latossolo Vermelho distroférrico, equiparando os valores Pt em ambos os manejos estudados.

Tabela 2. Média de umidade do solo (U), porosidade total (Pt), macroporosidade (Ma), microporosidade $(\mathrm{Mi})$ e resistência à penetração no anel (RP anel) por camada de solo, nos tratamentos preparo reduzido e plantio direto e nas posições do rodado do trator e entrerrodado, nas camadas de 0,00-0,10 e 0,10-0,20 m. Dourados, MS, UFGD, 2016. Mean of soil moisture $(U)$, total porosity (Pt), macroporosity (Ma), microporosity (Mi), soil density $(D s)$ and soil penetration resistance in the ring $(P R)$ per soil layer, in reduced tillage and notillage and in locations of tracks and between tracks treatments. Dourados, MS, UFGD, 2016.

\begin{tabular}{|c|c|c|}
\hline \multirow{2}{*}{ Tratamento } & \multicolumn{2}{|c|}{ Camada (m) } \\
\hline & $0,00-0,10$ & $0,10-0,20$ \\
\hline Preparo & \multicolumn{2}{|c|}{$\mathrm{U}\left(\mathrm{kg} \mathrm{kg}^{-1}\right)$} \\
\hline Reduzido & $0,23 \mathrm{a}$ & $0,22 \mathrm{a}$ \\
\hline Plantio direto & $0,21 \mathrm{~b}$ & $0,21 \mathrm{~b}$ \\
\hline \multicolumn{3}{|l|}{ Posição } \\
\hline Rodado & $0,21 \mathrm{~b}$ & $0,21 \mathrm{~b}$ \\
\hline Entrerrodado & $0,23 \mathrm{a}$ & $0,22 \mathrm{a}$ \\
\hline Preparo & \multicolumn{2}{|c|}{$\operatorname{Ma}\left(\mathrm{m}^{3} \mathrm{~m}^{-3}\right)$} \\
\hline Reduzido & $0,05 \mathrm{a}$ & $0,05 \mathrm{a}$ \\
\hline Plantio direto & $0,04 \mathrm{~b}$ & $0,04 \mathrm{a}$ \\
\hline \multicolumn{3}{|l|}{ Posição } \\
\hline Rodado & $0,04 \mathrm{a}$ & $0,05 \mathrm{a}$ \\
\hline Entrerrodado & $0,05 \mathrm{a}$ & $0,04 \mathrm{a}$ \\
\hline Preparo & \multicolumn{2}{|c|}{$\operatorname{Mi}\left(\mathrm{m}^{3} \mathrm{~m}^{-3}\right)$} \\
\hline Reduzido & $0,40 \mathrm{a}$ & $0,40 \mathrm{a}$ \\
\hline Plantio direto & $0,41 \mathrm{a}$ & $0,40 \mathrm{a}$ \\
\hline \multicolumn{3}{|l|}{ Posição } \\
\hline Rodado & $0,40 \mathrm{a}$ & $0,40 \mathrm{a}$ \\
\hline Entrerrodado & $0,41 \mathrm{a}$ & $0,40 \mathrm{a}$ \\
\hline Preparo & \multicolumn{2}{|c|}{$\mathrm{Pt}\left(\mathrm{m}^{3} \mathrm{~m}^{-3}\right)$} \\
\hline Reduzido & $0,46 \mathrm{a}$ & $0,45 \mathrm{a}$ \\
\hline Plantio direto & $0,45 \mathrm{a}$ & $0,44 \mathrm{a}$ \\
\hline \multicolumn{3}{|l|}{ Posição } \\
\hline Rodado & $0,44 \mathrm{a}$ & $0,45 \mathrm{a}$ \\
\hline Entrerrodado & $0,46 \mathrm{a}$ & $0,44 \mathrm{a}$ \\
\hline Preparo & \multicolumn{2}{|c|}{$\mathrm{RP}$ anel (MPa) } \\
\hline Reduzido & $3,27 \mathrm{a}$ & $4,34 \mathrm{a}$ \\
\hline Plantio direto & $4,00 \mathrm{a}$ & $3,90 \mathrm{a}$ \\
\hline Posição & & \\
\hline Rodado & $4,21 \mathrm{a}$ & $4,24 \mathrm{a}$ \\
\hline Entrerrodado & $3,10 \mathrm{~b}$ & $4,00 \mathrm{a}$ \\
\hline
\end{tabular}

As médias seguidas pela mesma letra na coluna, não diferem estatisticamente entre si pelo teste de SNK a 5\% de probabilidade. Means followed by the same lowercase letter in the column do not differ statistically from each other by the SNK test at $5 \%$ probability.

Fonte: Autoria própria. Own authorship. 
Ressalta-se que a ausência de diferença entre os tratamentos para a Ma na camada de 0,10-0,20 m (Tabela 2), pode ser explicada pela ação do implemento de preparo que, por atuar até a profundidade de $0,15 \mathrm{~m}$, criou camadas mais adensadas em subsuperfície. Esta avaliação leva em conta a amplitude da RP nas camadas de solo avaliadas, sendo de 35,81\% para a camada de 0,00-0,10 m e de $11,28 \%$ para a camada de 0,10-0,20 m; com uma variação média entre camadas no valor de $12,88 \%$. Do mesmo modo, os atributos físicos não diferiram entre as posições (rodado e entrerrodado), concordando com Cury et al. (2014), que estudaram o efeito do tráfego de máquinas em um Latossolo Vermelho eutroférrico, textura muito argilosa, na entrelinha e na linha de cana.

A Ma é influenciada diretamente pela compactação do solo imposta pelo tráfego de máquinas (BERGAMIN et al., 2010; VALADÃO et al., 2015) e/ou preparo do solo (ARCOVERDE et al., 2019c). No entanto, a não influência da posição de amostragem no preparo reduzido é compreensível, podendo ser explicada pela ação da ferramenta do implemento de preparo responsável por homogeinizar a estrutura na camada superficial do solo. Enquanto na área sob plantio direto, possivelmente ocorreram menores pressões dos rodados do trator com o solo em relação aos níveis de pressão suportados pelo solo no passado, não resultando em uma compactação adicional.

A resistencia mecânica do solo à penetração (RP) do anel diferiu entre as posições na camada de 0,00-0,10 m (Tabela 1), com maior valor na posição do rodado do trator quando comparado ao entrerrodado (Tabela 2), o que pode ter ocorrido em razão do acúmulo de pressões devido ao tráfego de máquinas para plantio e tratos culturais. Portanto, Souza et al. (2014) evidenciam a necessidade do controle das operações de cultivo ao estudarem o efeito da posição do tráfego utilizando sistema de piloto automático. Em geral, observam-se altos valores de RP nas camadas superficiais de solo, já em ciclos de cana-planta, o que pode comprometer o desenvolvimento radicular da cultura. Conforme Oliveira Filho et al. (2015) e Marasca et al. (2015) valores superiores a $4 \mathrm{MPa}$ representam limitação ao crescimento e desenvolvimento radicular da cana-de-açúcar.

No desdobramento da interação entre preparo e posição para densidade do solo (Ds) (Tabela 3), é possível observar maiores valores na camada de 0,10-0,20 m no solo sob plantio direto em relação ao sob preparo reduzido, bem como na posição do rodado do trator do que no entrerrodado, estando em concordância com Silva Junior et al. (2013), Cury et al. (2014) e Valadão et al. (2015), os quais afirmam que este fato pode ser atribuído às pressões mecânicas oriundas do tráfego de máquinas/implementos aliado ao não revolvimento do solo. A posição do tráfego influenciou a Ds apenas em sistemas de controle com piloto automático, situação que demonstra alto controle no tráfego para operações de cultivo na área do presente estudo, e que conforme Souza et al. (2014) isso pode repercutir positivamente no desenvolvimento da cultura.

Os valores de Ds na camada $(0,0-0,20 \mathrm{~m})$ no sistema plantio direto e na linha do rodado revelam alto grau de compactação em ciclo de cana-planta, uma vez que se encontram na faixa de 1,51 a 1,59 $\mathrm{Mg} \mathrm{m}^{-3}$ (Tabela 3), valores estes considerados máximos tanto por Sá et al. (2016) quanto por Oliveira et al. (2012) ao avaliarem a compactação em Latossolos de textura argilosa a muito argilosa. 
Tabela 3. Densidades do solo (Ds) por camada no desdobramento de preparo e posição de amostragem. Dourados, MS, UFGD, 2016. Soil density (Ds) per soil layer in unfloding of tillage and sample location. Dourados, MS, UFGD, 2016.

\begin{tabular}{ccccc}
\hline & \multicolumn{4}{c}{ Ds $\left(\mathrm{Mg} \mathrm{m}^{-3}\right)$} \\
\cline { 2 - 5 } Preparo do solo & \multicolumn{2}{c}{$0,00-0,10 \mathrm{~m}$} & \multicolumn{2}{c}{$0,10-0,20 \mathrm{~m}$} \\
\hline & Rodado & Entrerrodado & Rodado & Entrerrodado \\
Reduzido & $1,47 \mathrm{aA}$ & $1,41 \mathrm{aA}$ & $1,46 \mathrm{bA}$ & $1,48 \mathrm{aA}$ \\
Plantio direto & $1,53 \mathrm{aA}$ & $1,48 \mathrm{aA}$ & $1,54 \mathrm{Aa}$ & $1,49 \mathrm{aB}$ \\
\hline
\end{tabular}

Médias seguidas por letras iguais, maiúscula comparam tratamento preparo do solo dentro do local de amostragem e minúscula comparam tratamento local de amostragem dentro do preparo do solo, não diferem entre si pelo teste de SNK, a 5\% de probabilidade. Means followed by equal capital letters compare soil tillage treatment within the sampling site and lowercase letters compare sampling local treatment within the tillage do not differ from each other by the SNK test at 5\% probability.

Fonte: Autoria própria. Own authorship.

$\mathrm{Na}$ análise da RP média e máxima a campo, nas camadas $(0,00-0,10 ; 0,10-0,20 ; 0,20$ 0,30 e 0,30-0,40 m), observa-se que houve interação entre os fatores estudados, exceto na camada de 0,10-0,20 m (Tabela 4). Nesta é possível observar maiores valores de RP média no preparo reduzido (Tabela 5), o que pode ter ocorrido em razão do aumento da Ds (Tabela 3) pela ação do implemento de preparo, já que a U foi inferior no plantio direto (Tabela 2).

Tabela 4. Resumo da análise de variância da resistência à penetração determinada a campo média (RP média) e máxima (RP máxima) por camada de solo, nos tratamentos preparo do solo (P) e posição de amostragem (PS). Dourados, MS, UFGD, 2016. Abstract of the variance analisys of soil penetration resistance determined to field mean (PR mean) and maximum (PR maximum) per soil layer, in soil tillage $(P)$ and sampling location $(S P)$ treatments. Dourados, MS, UFGD, 2016.

\begin{tabular}{|c|c|c|c|c|}
\hline \multirow{2}{*}{ Fonte de variação } & \multicolumn{4}{|c|}{ Camada (m) } \\
\hline & $0,00-0,10$ & $0,10-0,20$ & $0,20-0,30$ & $0,30-$ \\
\hline & \multicolumn{4}{|c|}{ RP média } \\
\hline $\mathrm{P}$ & $15,47^{* *}$ & $8,866^{* *}$ & $8,259^{* *}$ & $12,83^{* *}$ \\
\hline PS & $202,6^{*}$ & $173,9^{* *}$ & $311,2^{* *}$ & $274,2^{* *}$ \\
\hline $\mathrm{P} \times \mathrm{PS}$ & $15,24^{* *}$ & $1,298^{\mathrm{ns}}$ & $9,076^{* *}$ & $34,69^{* *}$ \\
\hline \multicolumn{5}{|c|}{ RP máxima } \\
\hline $\mathrm{P}$ & $5,446^{*}$ & $2,79^{\mathrm{ns}}$ & $7,032^{* *}$ & $15,88^{* *}$ \\
\hline PS & $75,80^{* *}$ & $178,4^{* *}$ & $331,9^{* *}$ & $289,1^{* *}$ \\
\hline$P \times P S$ & $4,960^{* *}$ & $0,4719^{\mathrm{ns}}$ & $9,921^{* *}$ & $28,98^{* *}$ \\
\hline
\end{tabular}

A RP máxima não se diferenciou em relação aos preparos (Tabela 5), mas observou-se significância do fator posição, tanto para RP média como para RP máxima, com maiores valores no rodado, seguido do entrerrodado e da linha de plantio. Tal fato se deve ao tráfego de máquinas na entrelinha da cultura que acarreta aumento dos valores de RP e Ds, quando comparados às posições onde não houve pressão dos rodados do trator. Aliado a isso, em ambas as camadas de solo, houve menores valores de U na posição do rodado em relação ao entrerrodado do trator (Tabela 2). Para Cury et al. (2014) e Souza et al. (2014), maior RP na 
entrelinha e menor na linha de plantio, na camada de 0,00-0,40 m e 0,00-0,30 m, respectivamente; podem ser atribuidos à sulcação direta que cria ambiente com menor RP, independentemente do sistema de preparo do solo.

Na camada $(0,00-0,10 \mathrm{~m})$ observou-se, tanto para RP média como para RP máxima, maiores valores no preparo reduzido na linha do rodado do trator, o que foi observado também no entrerrodado e na linha de plantio nas camadas de 0,20-0,30 e 0,30-0,40 m (Tabela 6). Contudo, nas camadas subjacentes e, na linha do rodado, quando a RP (média e máxima) não foi inferior no preparo reduzido, esta foi igual ao plantio direto. Esses resultados evidenciam que em solos desestruturados há tendência de compactação nas camadas superficiais de solo pela ação da ferramenta de preparo; enquanto a ação do sulcador em solos mobilizados poderia contribuir com o adensamento das camadas subsuperficiais, elevando os valores de RP. Já na área sob plantio direto, os maiores valores de RP na linha do rodado e nas camadas subsuperficiais pode ser explicado principalmente pela ausência de preparo do solo.

Tabela 5. Resistência à penetração média (RP média) e máxima (RP máxima) determinada a campo na camada de solo de $0,10-0,20 \mathrm{~m}$, nos tratamentos preparo reduzido e plantio direto e nas posições do rodado do trator, entrerrodado e linha de cana. Dourados, MS, UFGD, 2016. Soil penetration resistance mean ( $P R$ mean) and maximum ( $P R$ maximum) determined of yield in soil layer of 0,10-0,20 m, in reduced tillage and no-tillage and in samplings of tracks, between tracks and planting row. Dourados, MS, UFGD, 2016.

\begin{tabular}{ccc}
\hline & \multicolumn{2}{c}{ Camada $(0,10-0,20 \mathrm{~m})$} \\
\hline Preparo & RP média $(\mathrm{MPa})$ & RP máxima $(\mathrm{MPa})$ \\
\hline Reduzido & $2,36 \mathrm{a}$ & $3,83 \mathrm{a}$ \\
Plantio direto & $2,12 \mathrm{~b}$ & $3,63 \mathrm{a}$ \\
\hline Posição & & \\
\hline Rodado & $3,18 \mathrm{a}$ & $5,31 \mathrm{a}$ \\
Entrerrodado & $2,11 \mathrm{~b}$ & $3,29 \mathrm{~b}$ \\
Linha & $1,43 \mathrm{c}$ & $2,59 \mathrm{c}$
\end{tabular}

Médias seguidas por letras iguais não diferem entre si pelo teste de SNK, a 5\% de probabilidade. Means followed by equal capital letters not differ from each other by the SNK test, at 5\% probability.

Fonte: Autoria própria. Own authorship.

A avaliação da RP máxima na linha do rodado em todas as camadas (Tabela 5 e 6), de acordo com Sá et al. (2016) permite identificar valores restritivos para o desenvolvimento radicular da cana-de-açúcar para solo argiloso, uma vez que, os valores estão acima de 3,8 MPa que, para um solo argiloso $\left(600 \mathrm{~g} \mathrm{~kg}^{-1}\right)$, podem representar redução da massa de raízes de cana-de-açúcar; conforme Cury et al. (2014) a RP tem 38\% de correlação negativa com a massa de raízes de cana; desta forma, os autores destacam a interferência de outros fatores no crescimento de raízes, como a própria morfologia do sistema radicular, cuja massa de raízes tende a diminuir em função da profundidade e distância da planta. Tal fato levanta um alerta considerando que os autores verificaram que $90 \%$ da massa de raízes estão localizadas no entrerrodado e no rodado do trator, e também nas camadas superficiais do solo. 
Tabela 6. Média da Resistência do solo à penetração média (RP média) e máxima (RP máxima) determinada a campo (RP) por camada de solo no desdobramento de preparo do solo e posição de amostragem. Dourados, MS, UFGD, 2016. Mean of Soil penetration resistance mean (PR mean) and maximum (PR maximum) determined of yield in soil layer in unfloding of tillage and sample location. Dourados, MS, UFGD, 2016.

\begin{tabular}{ccccccc}
\hline & \multicolumn{3}{c}{ RP média (MPa) } & \multicolumn{3}{c}{ RP máxima (MPa) } \\
\cline { 2 - 7 } & Rodado & Entrerrodado & Linha & Rodado & Entrerrodado & Linha \\
\hline & & & $0,00-0,10 \mathrm{~m}$ \\
Reduzido & $2,16 \mathrm{aA}$ & $1,18 \mathrm{aB}$ & $0,81 \mathrm{aC}$ & $4,19 \mathrm{aA}$ & $2,54 \mathrm{aB}$ & $1,87 \mathrm{aC}$ \\
Plantio direto & $1,63 \mathrm{bA}$ & $1,29 \mathrm{aB}$ & $0,67 \mathrm{aC}$ & $3,32 \mathrm{bA}$ & $2,66 \mathrm{aB}$ & $1,69 \mathrm{aC}$ \\
\hline & & \multicolumn{7}{c}{$0,20-0,30 \mathrm{~m}$} \\
Reduzido & $3,64 \mathrm{aA}$ & $2,40 \mathrm{aB}$ & $2,16 \mathrm{aB}$ & $5,28 \mathrm{bA}$ & $3,48 \mathrm{aB}$ & $3,15 \mathrm{aB}$ \\
Plantio direto & $3,83 \mathrm{aA}$ & $2,07 \mathrm{bB}$ & $1,75 \mathrm{bC}$ & $5,59 \mathrm{aA}$ & $2,90 \mathrm{bB}$ & $2,73 \mathrm{bB}$ \\
\hline & & \multicolumn{7}{c}{$0,30-0,40 \mathrm{~m}$} \\
Reduzido & $3,45 \mathrm{bA}$ & $2,66 \mathrm{aB}$ & $2,42 \mathrm{aC}$ & $4,76 \mathrm{bA}$ & $3,59 \mathrm{aB}$ & $3,23 \mathrm{aC}$ \\
Plantio direto & $3,88 \mathrm{aA}$ & $1,99 \mathrm{bB}$ & $2,06 \mathrm{bB}$ & $5,22 \mathrm{aA}$ & $2,68 \mathrm{bB}$ & $2,78 \mathrm{bB}$ \\
\hline
\end{tabular}

Médias seguidas por letras iguais, maiúscula comparam tratamento preparo do solo com local de amostragem $\mathrm{e}$ minúscula comparam tratamento local de amostragem com preparo do solo, letras iguais não diferem entre si pelo teste de SNK, a 5\% de probabilidade. Means followed by equal capital letters compare soil tillage treatment within the sampling site and lowercase letters compare sampling local treatment within the tillage do not differ from each other by the SNK test at 5\% probability.

Fonte: Autoria própria. Own authorship.

\section{CONCLUSÃO}

O preparo reduzido com gradagem pesada aumentou a macroporosidade na camada de $0,00-0,10 \mathrm{~m}$.

A porosidade total e a microporosidade não foram influenciadas quanto ao preparo do solo e à posição de amostragem.

Houve redução da resistência mecânica à penetração média e máxima a campo da posição do rodado, seguido do entrerrodado e da linha de plantio, respectivamente.

$\mathrm{Na}$ linha de plantio, ocorreram maiores valores de resistência à penetração média e máxima no preparo reduzido do que no plantio direto nas camadas de 0,20-0,30 e 0,30-0,40 m.

\section{AGRADECIMENTOS}

Os autores agradecem à UFGD, à CAPES, à FINEP e à FUNDECT, pelo apoio financeiro. À CAPES, pela concessão das bolsas de Doutorado e Pós-Doutorado ao primeiro autor. Ao CNPq, pela bolsa PQ concedida ao segundo autor. 


\section{REFERÊNCIAS BIBLIOGRÁFICAS}

ALVARES, C. A.; STAPE, J. L.; SENTElHAS, P. C.; GONÇALVES, J. L. M.; SPAROVEK, G. Köppen's climate classification map for Brazil. Meteorologische Zeitschrift, Stuttgart, v. 22, n. 6, p.711-728, 2013. Disponível em: https://www.schweizerbart.de/papers/metz/detail/22/82078/Koppen_s_climate_classification_ map_for_Brazil. Acesso em: 15 set. 2018.

ARCOVERDE, S. N. S.; SOUZA, C. M. A.; NAGAHAMA, H. J.; MAUAD, M.; CORTEZ, J.W.; ARMANDO, E. J. Growth and sugarcane cultivars productivity under notillage and reduced tillage system. Revista Ceres, Viçosa, v. 66, n. 3, p.168-177, 2019(a). Disponível em: http://www.scielo.br/scielo.php?script=sci_arttext\&pid=S0034-737X2019000300168. Acesso em: 18 nov. 2019.

ARCOVERDE, S. N. S.; SOUZA, C. M. A.; CORTEZ, J. W.; MACIAK, P. A. G.; SUÁREZ, A.H.T. Soil physical attributes and production components of sugarcane cultivars in conservationist tillage systems. Revista Engenharia Agrícola, Jaboticabal, v. 39, n. 2, p.216224, 2019(b). Disponível em: http://www.scielo.br/scielo.php?script=sci_abstract\&pid=S010069162019000200216\&lng=pt \&nrm=iso. Acesso em: 13 nov. 2019.

ARCOVERDE, S. N. S.; SOUZA, C. M. A.; SUAREZ, A. H. T.; COLMAN, B. A.; NAGAHAMA, H. J. Atributos físicos do solo cultivado com cana-de-açúcar em função do preparo e época de amostragem. Revista de Agricultura Neotropical, Cassilândia, v. 6, n. 1, p.41-47, 2019(c).

Disponível

em: https://periodicosonline.uems.br/index.php/agrineo/article/view/2761. Acesso em: 20 nov. 2019.

ARCOVERDE, S. N. S.; SOUZA, C. M. A.; ORLANDO, R. C.; SILVA, M. M.; NASCIMENTO, J. M. Crescimento inicial de cultivares de cana-de-açúcar em plantio de inverno sob preparos conservacionistas do solo. Revista Engenharia na Agricultura, Viçosa, v. 27, n. 2, p.142-156, 2019(d). Disponível em: https://periodicos.ufv.br/reveng/article/view/803. Acesso em: 18 nov. 2019.

ARCOVERDE, S. N. S.; SOUZA, C. M. A.; SILVA, M. M.; SOARES, M. A.; SANTOS, W. R.; SUÁREZ, A. H. T. Perfilhamento de variedades de cana-de-açúcar em sistemas conservacionistas de manejo do solo. Nucleus, Ituverava, v. 15, n. 2, p.349-356, 2018. Disponível em: http://www.nucleus.feituverava.com.br/index.php/nucleus/article/view/2749. Acesso em: 19 set. 2019.

BERGAMIN, A. C.; VITORINO, A. C. T.; FRANCHINI, J. C.; SOUZA, C. M. A.; SOUZA, F. R. Compactação de um Latossolo Vermelho Distroférrico e suas relações com o crescimento radicular do milho. Revista Brasileira de Ciência do Solo, Viçosa, v. 34, n. 3, p.681-691, 2010. Disponível em: http://www.scielo.br/scielo.php?script=sci_abstract\&pid=S010006832010000300009\&lng=en $\& n r m=i s o \&$ tlng=pt. Acesso em: 10 nov. 2018. 
CARVAlHO, L. A.; SILVA JUNIOR, A. A.; NUNES, W. A. G. A.; MEURER, I.; SOUZA JÚNIOR, W. S. Produtividade e viabilidade econômica da cana-de-açúcar em diferentes sistemas de preparo do solo no Centro-oeste do Brasil. Revista de Ciências Agrárias, Lisboa, v. 34, n. 1, p.200-211, 2011. Disponível em: http://www.scielo.mec.pt/scielo.php?script=sci_arttext\&pid=S0871-018X2011000100018. Acesso em: 15 out. 2018.

CURY, T. N.; MARIA, I. C.; BOLONHEZI, D. Biomassa radicular da cultura de cana-deaçúcar em sistema convencional e plantio direto com e sem calcário. Revista Brasileira de Ciência do Solo, Viçosa, v. 38, n. 6, p.1929-1938, 2014. Disponível em: http://www.scielo.br/scielo.php?pid=S010006832014000600027\&script=sci_abstract\&tlng=p t. Acesso em: 12 out. 2018.

MARASCA, I.; LEMOS, S. V.; SILVA, R. B.; GUERRA, S. P. S.; LANÇAS, K. P. Soil Compaction Curve of an Oxisol under Sugarcane Planted after In-Row Deep Tillage. Revista Brasileira de Ciência do Solo, Viçosa, v. 39, n. 5, p.1490-1497, 2015. Disponível em: http://www.scielo.br/scielo.php?script=sci_arttext\&pid=S0100-06832015000501490. Acesso em: 08 set. 2018;

OHASHI, A. Y. P.; PIRES, R. C. M.; RIBEIRO, R. V.; SILVA, A. L. B. O. Root growth and distribution in sugarcane cultivars fertigated by a subsurface drip system. Bragantia, Campinas, v. 74, n. 2, p.131-138, 2015. Disponível em: http://www.scielo.br/scielo.php?script=sci_arttext\&pid=S0006-87052015000200131. Acesso em: 08 set. 2018.

OLIVEIRA FILHO, F. X.; MIRANDA, N. O.; MEDEIROS, J. F.; SILVA, P. C. M.; MESQUITA, F. O.; COSTA, T. K. G. Zona de manejo para preparo do solo na cultura da cana-de-açúcar. Revista Brasileira de Engenharia Agrícola e Ambiental, Campina Grande, v. 19, n. 2, p.186-193, 2015. Disponível em: http://www.scielo.br/scielo.php?pid=S1415$43662015000200186 \&$ script=sci_abstract\&tlng=pt. Acesso em: 09 set. 2018.

OLIVEIRA, P. R.; CENTURION, J. F.; CENTURION, M. A. P. C.; FRANCO, H. B. J.; PEREIRA, F. S.; BÁRBARO JÚNIOR, L. S.; ROSSETTI, K. V. Qualidade física de um Latossolo Vermelho cultivado com soja submetido a níveis de compactação e de irrigação. Revista Brasileira de Ciência do Solo, Viçosa, v. 36, n. 2, p.587-597, 2012. Disponível em: http://www.scielo.br/scielo.php?script=sci_arttext\&pid=S0100-06832012000200028. Acesso em: 07 set. 2018.

RAMOS, B. Z.; PAIS, P. S. M.; FREITAS, W.A.; DIAS JUNIOR, M. S. Avaliação dos atributos físico-hídricos em um Latossolo Vermelho distroférrico sob diferentes sistemas de manejo - Lavras/Minas Gerais/Brasil. Revista de Ciências Agrárias, Lisboa, v. 36, n. 3, p.340-346, 2013. Disponível em: http://www.scielo.mec.pt/scielo.php?script=sci_arttext\&pid=S0871-018X2013000300009. Acesso em: 10 out. 2019.

ROSSETTI, K. V.; CENTURION, J. F. Sistemas de manejo e atributos físico-hídricos de um Latossolo Vermelho cultivado com milho. Revista Brasileira de Engenharia Agrícola e 
Ambiental, Campina Grande, v. 17, n. 5, p.472-479, 2013. Disponível em: http://www.agriambi.com.br/revista/v17n05/v17n05a02.pdf. Acesso: 20 set. 2018.

SÁ, M. A. C.; SANTOS JUNIOR, J. D. G.; FRANZ, C. A. B.; REIN, T. A. Qualidade física do solo e produtividade da cana-de-açúcar com uso da escarificação entre linhas de plantio. Pesquisa Agropecuária Brasileira, Brasília, v. 51, n. 9, p.1610-1622, 2016. Disponível em: http://www.scielo.br/scielo.php?pid=S0100204X2016000901610\&script=sci_abstract\&tlng= pt. Acesso em: 22 out. 2018.

SANTOS, D. H.; TIRITAN, C. S.; FOLONI, J. S. S.; FABRIS, L. B. Produtividade de canade-açúcar sob adubação com torta de filtro enriquecida com fosfato solúvel. Pesquisa Agropecuária Tropical, Goiânia, v. 40, n. 4, p.454-461, 2010. Disponível em: http://www.scielo.br/scielo.php?script=sci_arttext\&pid=S1983-40632010000400002. Acesso em: 22 set. 2019.

SANTOS, H. G.; JACOMINE, P. K. T.; ANJOS, L. H. C.; OLIVEIRA, V. A.; LUMBRERAS, J. F.; COELHO, M. R.; ALMEIDA, J. A.; ARAUJO FILHO, J. C.; OLIVEIRA, J. B.; CUNHA, T. J. Sistema Brasileiro de Classificação de Solos. 5. ed. Brasília: Embrapa, 2018. 187 p. Disponível em: https://www.embrapa.br/solos/busca-depublicacoes/ /publicacao/1094003/sistema-brasileirode-classificacao-de-solos. Acesso em: 18 out. 2018.

Silva JUNiOR, C. A.; CARVAlHO, L. A.; CENTURION, J. F.; OliveIRA, E. C. A. Comportamento da cana-de-açúcar em duas safras e atributos físicos do solo, sob diferentes tipos de preparo. Biosciencie Journal, Uberlândia, v. 29, n. 1, p.1489-1500, 2013. Disponível em: http://www.seer.ufu.br/index.php/biosciencejournal/article/view/15202. Acesso em: 22 set. 2018 .

SILVA, A. A.; CASTRO, S. S. Indicadores macro e micromorfológicos da qualidade física de um Latossolo Vermelho cultivado com cana-de-açúcar. Mercator, Fortaleza, v. 4, n. 3, p.169185, 2015.2 Disponível em: http://www.scielo.br/scielo.php?pid=S198422012015000300169\&script=sci_abstract\&tlng=p t. Acesso em: 16 set. 2018.

SOUZA, G. S.; SOUZA, Z. M.; SILVA, R. B.; ARAÚJO, F. S.; BARBOSA, R. S. Compressibilidade do solo e sistema radicular da cana-de-açúcar em manejo com e sem controle de tráfego. Pesquisa Agropecuária Brasileira, Brasília, v. 47, n. 4, p.603-612, 2012. Disponível em: http://www.scielo.br/scielo.php?script=sci_abstract\&pid=S0100204X2012000400017\&lng=pt\&nrm=iso. Acesso em: 13 set. 2018.

SOUZA, G. S.; SOUZA, Z. M.; SILVA, R. B.; BARBOSA, R. S.; ARAÚJO, F. S. Effects of traffic control on the soil physical quality and the cultivation of sugarcane. Revista Brasileira de Ciência do Solo, Viçosa, v. 38, n. 1, p.135-146, 2014. Disponível em: http://www.scielo.br/scielo.php?script=sci_arttext\&pid=S0100-06832014000100013. Acesso em: 13 set. 2018.

TEIXEIRA, P. C.; DONAGEMMA, G. K.; FONTANA, A.; TEIXEIRA, W. G. Manual de métodos de análise de solo. 3.ed. Brasília: Embrapa Informação Tecnológica, 2017. 573 p. 
VALADÃO, F. C. A.; WEBER, O. L.; VALADÃO JÚNIOR, D. D.; SCARPINELLI, A.; DEINA, F. R.; BIANCHINI, A. Adubação fosfatada e compactação do solo: sistema radicular da soja e do milho e atributos físicos do solo. Revista Brasileira de Ciência do Solo, Viçosa, v. 39, n. 1, p.243-255, 2015. Disponível em: http://www.scielo.br/scielo.php?pid=S0100$06832015000100243 \&$ script=sci_abstract\&tlng=pt. Acesso em: 14 set. 2018. 